\title{
URBANIZACIÓN, CONSERVACIÓN Y RURALIDAD en los cerros Orientales de Bogotá
}

\author{
Carlos Andrés Meza \\ Investigador del Instituto Colombiano de Antropología e Historia (ICANH) \\ cmeza@icanh.gov.co
}

\begin{abstract}
Resumen

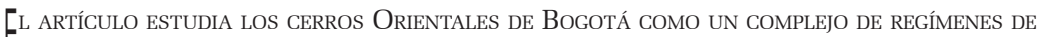
-territorialidad y experiencias histórico-sociales heterogéneas y conflictivas entre sí a lo largo del tiempo. La cuenca del río Teusacá es el contexto micro regional en la transición entre Bogotá y la región oriental, y sirve de caso para identificar la superposición y el conflicto de territorialidades asociadas a la conservación de la naturaleza, la expansión urbana y la ruralidad. Un análisis de los diferentes regímenes de construcción territorial a lo largo del siglo veinte permite vislumbrar la encrucijada y el conflicto que caracteriza a los cerros orientales de Bogotá en este nuevo siglo.

PAlabras Clave: paisaje, territorialidad, conservación, urbanización, campesinos, conflicto.
\end{abstract}

\section{Crossroads AND CONFlict. Urbanization, CONSERVATION AND RURAlity in the Eastern mountains of Bogotá.}

\begin{abstract}
THE

HE ARTICLE EXPLORES THE EASTERN MOUNTAINS OF BOGOTÁ AS A COMPLEX OF TERRITORIALITY REGIMES and socio-historical heterogeneous and conflicting experiences through time. The Teusacá river basin is the micro regional context in the transition between Bogotá city and the Eastern plains. It serves as a case study to identify overlapping and conflicting territorialities associated with nature conservation, urban expansion and rural life. The analysis of the construction of different territorial regimes during the last century allows a glimpse at the dilemmas and conflicts that characterize the Eastern mountains of Bogotá in this new century.

KEY WORDS: Landscape, territoriality, conservation, urbanization, peasants, conflict.
\end{abstract}

\section{Revista Colombiana de Antropología}

Volumen 44 (2), julio-diciembre 2008, pp. 439-480 
A Alfonso Molano, caminante y habitante de los cerros Orientales, fallecido en agosto de 2006

\section{INTRODUCCIÓN}

A CUENCA DEL RÍO TEUSACÁ ES UN TERRITORIO QUE FORMA PARTE DE LOS cerros Orientales de Bogotá. Hace poco más de treinta años, el -entonces Distrito Especial lo convirtió en área protegida y desde entonces se identifica con la categoría de "reserva forestal protectora", lo que significa que se trata de una zona que por el valor de sus elementos físicos -agua y suelo- y bióticos -vegetación y fauna-debe ser conservada permanentemente con bosque, ya sea para la preservación de las aguas, los suelos, la fauna silvestre y el paisaje, o bien, para el desarrollo de la economía forestal como en su momento lo estipuló la ley 2a de I959, de reservas forestales de la nación. Ubicada entre los cerros Orientales, la cuenca del río Teusacá ha sido también un hito de paso en el tránsito histórico desde el altiplano hacia los pueblos de los Llanos orientales. La población campesina que hoy la habita es el resultado de dinámicas de movilidad inscritas en el marco de relaciones entre una urbe que creció recostada sobre los cerros Orientales, pero persiguiendo los caminos del occidente con rumbo al valle del río Magdalena.

Desde finales del siglo veinte, la sabana se viene modernizando con la conurbación característica por la expansión, el acceso y la conectividad entre la metrópoli y los municipios circundantes. La contraparte del salto agroindustrial en la zona plana de occidente está en las montañosas alto andinas. Allí, las viejas rutas de oriente, la historia extractiva del carbón para abastecer a la ciudad en épocas pasadas y el minifundio son marcadores de una territorialidad rural en contrapunteo con la expansión urbana del borde oriental de la ciudad, que ha unido a barrios y veredas. El valle que forma el Teusacá parecía alejado de la expansión del borde urbano, hasta que nuevas dinámicas de ocupación en forma de lujosos chalets o grandes fincas de propietarios ausentes evidenciaron un encuentro entre lo rural y la ciudad, mediadas por relaciones de servidumbre. Las múltiples formas de uso y ocupación a partir de eventos y de sucesos dinamizadores de 
la relación entre la ciudad y los cerros Orientales revelan una problemática de superposiciones territoriales en el paisaje.

Al hablar de paisaje me refiero al resultado de procesos históricos, sociales, políticos, económicos y ambientales que interactúan en el modelamiento del espacio. El geógrafo estadounidense Carl Sauer, estudioso de la relación diacrónica y sincrónica entre la sociedad y la naturaleza, sintetizó la elaboración física y simbólica de hábitats mediante el trinomio: cultura (agente)-naturaleza (medio)-paisaje (resultado) (Sauer, I963). Se trata de una geografía histórica en la cual el paisaje es resultante del despliegue de múltiples territorialidades a través del tiempo. Con la noción de territorialidad aludo a ejercicios discursivos y materiales que revelan una lógica de construcción del espacio. Un conjunto de sucesos descritos permiten comprender formas de interrelación con el entorno. Así, el paisaje es la cara visible de un territorio y un territorio es la creación cultural e histórica de un espacio; las políticas públicas territoriales y las acciones sociales, por ejemplo, son elementos que moldean el paisaje (Ardila, 2006). En ese sentido, no es posible comprender esa cara visible si no se entiende como el producto del peso de historias, ideologías, economías y relaciones sociales, como sucede con los problemas asociados al ordenamiento territorial de los cerros Orientales. Estos son el resultado de las relaciones y superposiciones conflictivas entre territorialidades que comparten y compiten por el mismo lugar y por el modelamiento del ambiente, como son las políticas de conservación y las dinámicas de ocupación campesina, ambas relacionadas con la expansión urbana. El resultado es que los cerros son un paisaje conflictivo, un territorio de frontera que se caracteriza por la encrucijada y la confrontación. Es discutible decir, por ejemplo, que se trata de "ecosistemas estratégicos" o de "reservas", porque se desconocerían las dinámicas de ocupación en barrios y veredas, pero esto no es menos problemático que la urbanización del borde de la ciudad que se erige sobre el bosque oriental.

Estudiar el entrecruce de territorialidades constituye una crítica al dualismo naturaleza-sociedad que se extiende a la dicotomía entre campo y ciudad, que ha ocasionado una ruptura en la relación dialéctica de adaptación y transformación entre los pueblos y los sistemas naturales, socavando la relación sociedad-entorno y presentando a la naturaleza como un mundo en equilibrio, roto por la impertinencia humana (Leal, 2002) o bien, como mero recurso que puede ser objeto de explotación y dominio de las ciencias y de la producción. Así, el conserva- 
cionismo y el desarrollismo, aun cuando opuestos, parecen ser dos caras de una misma moneda en donde la naturaleza es fija y estática. Esto, nos dice Claudia Leal (2002: 127), le roba al ambiente su historia y va en contravía de los objetos mismos y de la historia ambiental. La concepción desarrollista de la naturaleza se sustenta en el paradigma antropocéntrico, racionalista e instrumental, que se consolidó durante la modernidad a partir de los siglos dieciocho y diecinueve. La concepción conservacionista por su parte, surge del paradigma ecocéntrico, en el que la naturaleza es concebida como ente autónomo con una organización ecosistémica compleja que se imagina totalmente escindida de los procesos sociales de valoración y de apropiación de la naturaleza (Amérigo y González, 1999). En el paradigma ecocéntrico radical, la cultura parece más bien una intromisión extraña en el orden de la naturaleza. Los seres humanos son entonces invasores y manipuladores de los ecosistemas al desplegar una plataforma tecnológica que desestructura el orden prístino. Tanto el paradigma desarrollista, que instrumentaliza la naturaleza, como el conservacionista, que la ve en sí misma como capital, son construcciones de la cultura convertidas en políticas que pretenden resolver las situaciones problemáticas que derivan de epistemologías naturalistas y antropocéntricas.

Por otra parte, la oposición entre lo rural y lo urbano parece congruente con el supuesto civilizatorio y de construcción de órdenes espaciales rígidos a los cuales se asocia la presencia de grupos humanos rígidamente diferenciados (Tocancipá-Falla, 2005). Los espacios rurales son habitados por campesinos, asociados con la permanencia, mientras que en las ciudades residen comunidades urbanas que se suponen cambiantes. Esta dualidad es el reflejo de cómo las teorías de la complejidad y de la evolución unilineal decimonónicas reificadas en el discurso civilizatorio del desarrollo y del tercer mundo de mediados del siglo veinte establecen jerarquizaciones y taxonomías que suponen una enorme violencia epistémica sobre el estudio de las sociedades rurales. Los esencialismos en la conceptualización de lo campesino se pueden rastrear en la genealogía del concepto, por ejemplo, la tradición sociológica ha asociado a los campesinos con la vida en el campo, el trabajo de la tierra, la rusticidad y la residencia fuera del espacio de la ciudad (Tocancipá-Falla, 2005: 7). Todas estas alusiones distan de las condiciones particulares que pretendo analizar y que se refieren a la interfase entre dos tipos geográficos 
aparentemente bien diferenciados como son el campo y la ciudad. Estos territorios "resbaladizos", en situación transicional y de permanente transformación han recibido diversas denominaciones que aluden a una definición por indefinición: la periferia urbana, el rur-urbano, la "ciudad difusa", la frontera campo-ciudad, la "ciudad dispersa”, territorios de borde, borde urbano/periurbano o el contorno de la ciudad (Capel, I994 citado en Barski, 2005: I; Álvarez, 1999). En este contexto, el término campesino opera para los actores rurales como una conciencia históricamente situada en relación con las transformaciones del paisaje asociadas con fenómenos de expansión urbana, extracción de recursos naturales y conversión del espacio habitado en reserva forestal. Como lo señala Tocancipá-Falla (2005) lo campesino se convierte en una forma de expresión política, utilizada como mecanismo de acción reivindicativa y movilización de derechos de ocupación y el ejercicio de su territorialidad en un marco de invisibilidad y marginalidad al que han sido sometidos por el estado.

La problemática de la cuenca del río Teusacá entraña la compleja articulación entre órdenes rurales y urbanos y entre concepciones muy particulares y dominantes de naturaleza y sociedad. Incluso, si se habla de la naturaleza como algo aprehendido, socializado y mediado por la cultura, podría decirse que, en un sentido epistemológico, no existe una única naturaleza socialmente construida, sino múltiples naturalezas que se constituyen en niveles históricos, geográficos y sociales diferentes (Saurí y Boada, 2006). Así lo demuestran las dinámicas de la apropiación de esas laderas de alta montaña y el telón de fondo que son los cerros Orientales. Este borde peri-urbano durante años se mantuvo al margen del crecimiento de la ciudad por sus condiciones climáticas y por sus pendientes, pero se convirtió en espacio de vida y recreación de prácticas ecológicas, económicas y socioculturales para la población campesina nativa y emigrante de otras regiones. Paralelamente, ha sido enclave de diversas actividades extractivas de gran impacto sobre los recursos minerales y vegetales. Si en otro tiempo la gente de la ciudad percibía los cerros como el "monte" -espacio no-domesticado-, o como la gran “despensa” de leña, carbón y agua, hoy las nuevas generaciones ven en ellos un territorio degradado que materializa y hace palpable la crisis ambiental.

La propuesta de historia ambiental de este artículo busca dar sentido a la subjetivación y sujeción inherentes a la identidad 
campesina, e intenta hilvanar los fenómenos y sucesos que subyacen a la idea política de los cerros Orientales como oferta de espacio público, de recursos naturales, así como lugar de recreación y de identidad cultural para Bogotá. Monserrate y Guadalupe, la laguna el Verjón, donde nace el río Teusacá, o la vía a La Calera, por ejemplo, son referentes que hablan de una historia poco conocida de territorialidades campesinas, extractivas, de reserva y expansión urbana invisible e intersticial. El artículo está dividido en tres secciones: la primera trata del contexto biogeográfico e histórico de los cerros Orientales y de la cuenca del río Teusacá. La información empírica e histórica acerca de la extracción de recursos naturales, la expansión urbana, la conservación del bosque oriental y la ruralidad pretende identificar regímenes de territorialidad en conflicto. La segunda parte procede a caracterizar el conflicto resultante de la confrontación entre las lógicas de apropiación territorial mencionadas. En la tercera y última, el artículo se refiere al conocimiento situado y a los espacios de experiencia y construcción de una territorialidad por parte de los campesinos de los cerros Orientales, en su continuo discurrir entre los umbrales de la ciudad y los del bosque oriental.

La noción de conocimiento situado que empleo sigue al historiador alemán Reinhart Koselleck, respecto a la conciencia que forman las transiciones históricas en las sociedades. Se trata de una tensión entre espacios de experiencia y horizontes de expectativa que incide en la expresión de pensamientos, elaboración de memorias e ideas políticas que hacen comprensibles diferentes narrativas (Koselleck, I993: 336). Donna Haraway (I995) sostiene que esta tensión deriva de diversos aspectos sociohistóricos que determinan la posición del sujeto, que en el caso del sujeto campesino hace parte de una de las múltiples realidades sociales de los cerros Orientales. Su experiencia es el resultado de la encrucijada territorial y esta se puede recoger a partir de hitos relevantes en el reconocimiento del paisaje, que implica recorrer, recordar y narrar un territorio para repensar algunas ideas que existen acerca del mismo. La patrimonialización de los cerros Orientales, por ejemplo, es una

I. En 2008, la Secretaría Distrital de Planeación publicó la consultoría que llevó a cabo para la creación de un corredor ecológico y recreativo en los cerros Orientales (Wiesner et al., 2008).

institucionales ambientales, sociales y culturales del distrito y la región ${ }^{1}$. No obstante, prima el desencuentro entre objetivos de idea política derivada de su valor ecológico, social y cultural, que aparece de diversas formas en múltiples intervenciones 


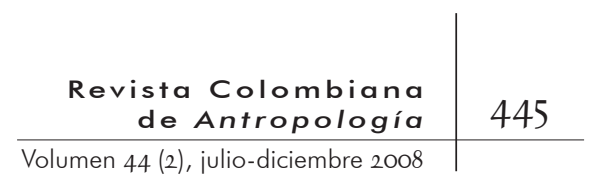

preservación ecológica, sostenibilidad ambiental, equidad social y sustentabilidad económica.

Este artículo surge como una reflexión y un análisis crítico de mi experiencia de dos años de trabajo e investigación aplicada a los procesos de formulación de planes de ordenamiento y manejo de los cerros Orientales. De mi participación como consultor en proyectos con los sectores rurales de Bogotá derivan las notas finales acerca de la experiencia y los horizontes que caracterizan la presencia de esta población que habita en los gélidos contornos montañosos de la capital. Al final, expondré algunas ideas para pensar alternativas a las tensiones urbano-rurales, así como las visiones antropocéntricas y ecocéntricas que matizan el concepto de sostenibilidad priorizando la sostenibilidad del subsistema humano sobre el biótico, en el caso de la primera, o del subsistema biótico sobre el humano, en el caso de la segunda.

\section{Los cerros Orientales y el Teusacá}

L TERRITORIO QUE COMPRENDE LOS CERROS ORIENTALES ES UNA FRANJA

- montañosa de I4.00o hectáreas, que se sitúa entre la sabana de -Bogotá y la región que comunica con las tierras calientes de los Llanos orientales. Los cerros forman una especie de barrera natural que circunda a la ciudad en su costado oriental y significan la principal zona verde y fuente de producción de oxígeno para la capital. Poseen una gran diversidad de especies de flora y fauna, que soportan la consolidación de distintos ecosistemas como los páramos -entre 3.300 y 3.800 msnm-, los subpáramos -entre 3.200 y 3.400 msnm- y los bosques alto-andinos -entre 2.700 y $3.000 \mathrm{msnm}-$. Su estructura ecológica ha configurado un encadenamiento vertical de estos tres ecosistemas que ha preservado algunos remanentes de bosque alto andino -II,7 \% del área total-y un extenso cordón de páramo -I8,3\% del área total(Sanclemente, 2004). Mas allá del borde urbano, donde acaba la ciudad y comienzan las montañas, se encuentra la cuenca del río Teusacá que hace parte del perímetro urbano de Bogotá. El escenario fisiográfico de la cuenca se ordena en torno a la laguna del Verjón alto, que está en el páramo de Cruz Verde a 3.300 msnm (CAR, I999). De allí se desprende el hilo de agua que da origen al río Teusacá y que desciende por la hondonada recogiendo aguas 
de decenas de quebradas que le tributan como las quebradas Santos, Carrizal, Raizal, El Coral, Farías, León, El Portillo, Turín, Honda y El Juncal (véase el mapa). El río Teusacá desemboca en el Bogotá, pero antes su represa forma el embalse San Rafael que tiene como fin asegurar el suministro adecuado de agua a Bogotá y a los municipios aledaños. El río Teusacá es eje ordenador de dos vertientes: la de occidente que limita con Bogotá y la de oriente que es adyacente a Choachí. Más al norte, la cuenca media atraviesa el municipio de La Calera, donde se encuentra localizado el embalse de San Rafael. Sopó y Tocancipá conforman su parte baja, donde el recurso es utilizado principalmente con fines de riego y abastecimiento doméstico. Dentro de la cuenca alta y media encontramos las veredas Verjón alto y Verjón bajo localizadas en una zona de frontera, donde tienen influencia los municipios de La Calera, Sopó y Guasca -al norte-, Choachí y Ubaque -al oriente- el distrito capital con localidades de Santa Fé y Chapinero, al occidente y los cerros de Usme, al sur.

MAPA

Cuenca Media del Río TeusacÁ

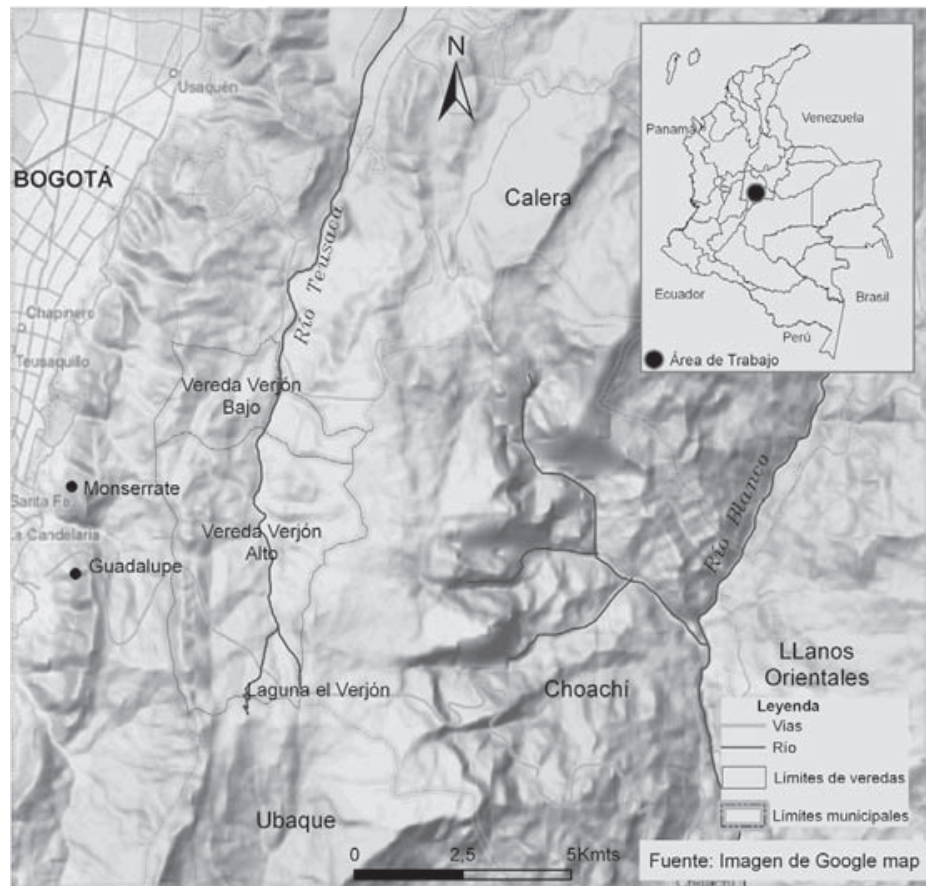




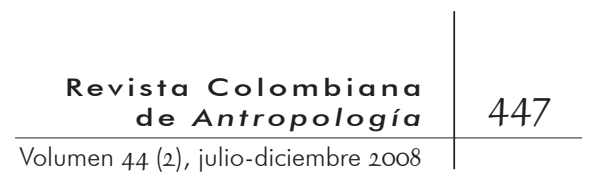

\section{La movilidad y la configuración del territorio}

A LO LARGO DEL TIEMPO, LA CUENCA ALTA DEL RÍO TEUSACÁ y SUS ACTUAles veredas han formado parte de una estructura de intercambio económico y cultural coherente con sus características de lugar de paso entre la sabana del altiplano y la región oriental. En el marco de una estrategia de asentamiento disperso, movilidad y control territorial, los indígenas muiscas hicieron del Teusacá un eje conector importante en la dinámica comercial e interétnica entre los Andes y los Llanos. Como otras culturales andinas, los muisca practicaban la microverticalidad, consistente en el aprovechamiento de la variedad de pisos térmicos y eco nichos que se dan en los ecosistemas templados, alto-andinos y de páramo (Herrera, 1999). Para ello precisaron de una red de caminos que les permitiera realizar recorridos entre franjas altitudinales; de ahí que la cuenca del río Teusacá esté demarcada por senderos de origen prehispánico que luego fueron retomados por los españoles para continuar las mencionadas relaciones de intercambio comercial con el oriente. Uno de esos senderos es el camino entre Monserrate y Choachí que conecta con la ruta de peregrinación al cerro tutelar y que luego atraviesa la cuenca en dirección oeste-este.

En el altiplano, los cronistas describieron caminos que salían desde las tierras altas hacia el piedemonte llanero (Simón, I98I, 2: 8I; Piedrahíta, I973 I: 63), y tres documentos de fines del siglo dieciséis mencionan caminos muiscas y dos hablan de "caminillos” en Teusacá. Aquellos que comunicaban las tierras altas con el piedemonte llegaban a pueblos como Súnuba o Somondoco, comunidades que suministraban algodón y coca a los grupos que ocupaban pisos térmicos más altos (Langebaek, I987: 82-87). Mucho se ha discutido acerca de la funcionalidad que tuvieron los caminos en la época prehispánica: algunos historiadores aseguran que no sólo permitían el acceso a terrazas de cultivo y el trueque con poblaciones vecinas, sino que los caminos de oriente tenían un carácter ceremonial y que, en ese sentido, su función era comunicar aldeas con santuarios (Piedrahíta, I973). También estaban asociados a la reproducción de estructuras organizativas tribales mediante rituales como las carreras que efectuaban los nobles guerreros de la sociedad muisca. Esas territorialidades tuvieron lugar en la laguna del Verjón alto y el río Teusacá; de la primera se dice que fue lugar de pagamento de los muiscas, dentro de su dinámica de culto al agua. Entretanto, el río era el 
escenario de las carreras que efectuaban los guechas o guerreros que hacían parte del anillo militar territorial que los muisca había conformado en torno al Zipa (Mariño y Peña, 2002).

Ya en la época colonial, el nuevo orden de sociedad impuesto por los españoles se relacionó de manera distinta con la franja montañosa de oriente. Esta relación se caracterizó por el sistema de encomienda y haciendas en tierras que eran apropiadas como despensa de recursos naturales, como tránsito entre Santafé y los pueblos de oriente (Therrien, I992). Los españoles convirtieron en reales los caminos que comunicaban a la sabana con la serranía oriental y la cuenca devino un territorio periférico. En cierto sentido, esa dinámica urbano-regional quedó plasmada en las pinturas costumbristas de los siglos dieciocho y diecinueve, que resaltan la connotación del boquerón del río San Francisco como puerta de entrada a la región oriental. Durante la época colonial, entre Monserrate y Guadalupe, los cerros se convirtieron en cinturón de viviendas para poblaciones indígenas y mestizas (Vargas y Zambrano, I990).

Siglos más tarde-finales del diecinueve y comienzos del veinte- las familias Samper, Morris Gutt, Nates y Fajardo extendieron sus propiedades en un área que iba desde Monserrate hasta la cuenca del río Teusacá. Fueron estas familias quienes incentivaron la extracción de leña y de carbón para el consumo urbano. Los trabajadores y aparceros de estas haciendas de encargo ${ }^{2}$ provenían de regiones lejanas como Santander y Boyacá, pero una buena parte era de la región oriental de Cundinamarca. Sus descendientes sostienen que las grandes familias fueron cediendo en pago por servicios, otorgando o vendiendo el terreno a sus trabajadores cuyos apellidos eran Bravo, Fonseca, Rico y Garzón, entre otros ${ }^{3}$. Así, la cuenca del río Teusacá fue poblada dentro de

2. Dado que los predios en propiedad de las familias Moris Gutt y compañía se caracterizaban por el ausentismo de sus dueños, estos fueron encargadas a la gente de la zona o que llegó por la oferta de trabajo que generó el carbón. En la actualidad existen en las veredas suburbanas, grandes predios en encargo (Mesa et al., 2005).

3. Entrevista con Cristino Bravo, 3 de mayo de 2006. una dinámica de movilidad de mestizos y campesinos pobres en torno a ofertas de trabajo asociadas con el abastecimiento de la ciudad. La dinámica de intercambio comercial entre las regiones de oriente se mantuvo viva teniendo a la cuenca del Teusacá como principal corredor; por eso, en la década de I920 se adecuó el camino real, y antes prehispánico, que de Monserrate llevaba a Choachí (Ramírez, 
2005). Las redes de antiguos caminos prehispánicos y reales que sirvieron al control económico y político de los indígenas y de la sociedad colonial se constituyeron en una impronta de las estrategias adaptativas desplegadas por los pobladores campesinos del Teusacá para establecer relaciones cotidianas entre la ciudad y el bosque oriental.

(...) aquí en ese entonces bajábamos con los animales (....) eran achucuas de barro que lo enterraban a uno hasta la cintura. Todo eso no era conocido de la ciudad lo mismo que los animales. Nosotros bajábamos a pie por el camino que venía desde Bogotá en la casa quinta de Bolívar y que subía por Monserrate y que llegaba a un alto que se llama Frailejonal, luego a la quebrada de Santos, el río Teusacá y que cogía la ladera hasta llegar a Choachí (entrevista con Miguel Pineda, 6 de junio de 2006).

\section{LA DESPENSA DE RECURSOS DEL BOSQUE}

A CONFIGURACIÓN DEL TEUSACÁ COMO TERRITORIO DESPENSA SURGIÓ A PARTIR de las relaciones que estableció la sociedad colonial asentada -al pie de los cerros Orientales. Con el establecimiento de pueblos de indios y de instituciones como la mita urbana ${ }^{4}$ y la encomienda, los colonizadores aseguraron la mano de obra de los indios y, de paso, su reducción demográfica como consecuencia de los trabajos forzados. Dichas actividades de sujeción incluye-

4. Desde el siglo dieciséis, la mita urbana se instauró como un derecho de los vecinos de Santafé de usufructuar la mano de obra indígena para diversos beneficios, entre ellos el aprovisionamiento de leña. Ello significó una pugna constante entre vecinos de la ciudad, representados por sus autoridades, y los encomenderos por el control del trabajo indígena. La mita urbana simbolizó el enfrentamiento entre la ciudad y el campo que acarreó la rápida desaparición de los indios (Trejos, 2006). ron el aprovisionamiento de leña para la construcción de las viviendas y como recurso energético extraído del bosque. La situación se extendió mucho después que desapareciera la colonia, como quedó consignado entre I879 y I880 en las crónicas semanales publicadas por Eugenio Díaz en el periódico capitalino El Bien Social:

(...) Al oriente de Bogotá hay una inmensa extensión de terreno cubierto de matorrales, de donde sacan los elementos de su subsistencia los carboneros y leñadores que proveen de combustible la 
vecina ciudad. En aquella comarca, situada a espaldas de los cerros Monserrate y Guadalupe que dominan a Bogotá, predomina el aspecto selvático y triste. El uvo camarón y el de anís, el tagua, el chucua, el arrayán, el encenillo, el tuno esmeralda y el laurel adornan y forman los bosquecillos que se extienden bordeando las fuentes o en las caídas de la serranía. Estos bosques van desapareciendo, porque los leñadores los talan sin discernimiento, y al propio tiempo que el paisaje toma un aspecto más triste, la vecina ciudad va perdiendo la abundancia y pureza de sus aguas. Otro tanto sucede con los chuscales, que sirven para hacer los cielos rasos de las casas de Bogotá (...) (El Bien Social, I879-I880).

El deterioro ambiental que el cronista percibe a finales del siglo diecinueve se relaciona con el incremento de actividades extractivas promovidas principalmente por familias dueñas de grandes haciendas en los cerros, que llegaron tras la oferta y demanda de recursos forestales y se relacionaron con el bosque en tanto recurso susceptible de ser explotado. En la década de I950, el bosque y sus pobladores paramunos seguían abasteciendo de recursos energético a la ciudad mediante el comercio de leña de cuartillo y carbón de encenillo y tuno. La venta del carbón vegetal sólo se detendría definitivamente con la aparición de la energía eléctrica y del cocinol a finales de los años I970 (Ramírez, 2003).

Otro fenómeno que coadyuvó en la configuración de la territorialidad extractiva fue el proceso de expansión urbana que demandó nuevos materiales de construcción y que propició que grandes sectores de las faldas de los cerros Orientales fueran utilizados como chircales y canteras, sobre todo en el borde urbano, como lo evidencia la sucesión de un régimen de apropiación territorial de fincas y estancias de encargo que fueron parceladas y loteadas para convertirse en fuentes de materiales. A partir del auge de la minería en los cerros, una de las familias terratenientes de finales del siglo diecinueve (Samper Agudelo) fundó en Igo9 la fábrica de Cementos Samper sobre la carretera noroeste que une a Bogotá con el municipio de Sopó en el sitio llamado Siberia (Universidad de los Andes-Cifa, I999). En la vereda suburbana y la cuenca del río Teusacá no se presentaron muchos casos de canteras, pero ello no impidió que tales actividades dejaran una huella en el paisaje.

Años mas tarde, hacia la década de 1970, la Corporación Autónoma Regional de Cundinamarca (CAR), sembró en los cerros cientos de hectáreas con plantaciones forestales de pino pátula y 
pino candelabro, ambas especies exóticas que hoy se consideran sumamente nocivas para los ecosistemas del bosque alto-andino (Ramírez, 2005). Muchas teorías se han desarrollado alrededor de este suceso histórico que no sólo tuvo lugar en la cuenca del río Teusacá, sino en todos los cerros Orientales. Alfonso Molano sostenía que:

(...) Eso fue un negocio que hicieron entre la empresa maderera Triplex Pizano y la CAR. La idea era que la empresa daba las semillas y la CAR sembraba las plantaciones con la promesa que la empresa los compraría a determinada edad con el objeto de explotarlos económicamente porque de ahí saldría papel y cartón. Sin embargo, la promesa de Triplex Pizano no prosperó y los pinos se quedaron ahí creciendo y haciéndole daño a la cuenca del Teusacá. Eso es lo que pasa con las acciones que emprende el gobierno y que no tienen continuidad. De eso no hay memoria (...) (entrevista con Alfonso Molano, I5 de junio de 2006).

Las plantaciones de pinos sembradas desde la década de 1970 son un buen referente de los proyectos de sustentabilidad forestal en donde el bosque es, ante todo, un recurso explotable. Pero no sólo eso. En tanto su explotación no llegó a realizarse, los bosques de estas especies crecieron y su expansión fue auspiciada por las instituciones apoyándose en criterios paisajísticos de reforestación que buscaban recrear en los cerros bosques de coníferas propios de las latitudes nórdicas. En la actualidad, el plan de manejo de los cerros que formuló la CAR y que dio a conocer en abril de 2006 considera que las plantaciones con especies exóticas son áreas destinadas a la restauración ecológica, lo cual implica la sucesión de especies de pinos por vegetación nativa ${ }^{5}$. Al convertirse en hecho histórico en la larga duración de una política de reforestación desplegada por la autoridad ambiental que en la actualidad 5. Resolución CAR II4I del I2 de abril de 2006, por la cual se adopta el Plan de manejo de la zona de reserva del bosque oriental.

privilegia la conservación, las

organizaciones de la sociedad civil, incluidas las que representan a los campesinos de Bogotá, se refieren a las plantaciones pineras en términos de sus impactos en la desaparición de la cobertura vegetal nativa y las fuentes de agua. La percepción del cambio en el paisaje en el contexto de reivindicaciones territoriales ha servido en la construcción discursiva de lo ecológico por parte de los campesinos de los cerros. Lo importante de reseñar aquí 
es el papel que desempeña el conocimiento de los campesinos sobre la forma como cambió el paisaje de los cerros y que va a ser muy importante en la producción de narrativas que confronten la contradicción de la institucionalidad ambiental al generar ella misma uno de los mayores deterioros ecológicos.

\section{La conservación del bosque oriental}

EN LA TENDENCIA CONSERVACIONISTA, LAS ÁREAS RURALES, ADEMÁS DE SER perferias urbanas, colindan o se encuentran en territorios que por sus características bióticas, económicas y sociales son considerados áreas protegidas. En el contexto urbano-regional, las áreas protegidas se asumen desde una perspectiva ecologista y biocéntrica que se fundamenta en políticas de reapropiación de la naturaleza orientadas hacia la preservación de los procesos ecológicos esenciales. En esta lógica, la conservación in situ de los recursos naturales plantea la necesidad de incrementar la oferta natural para la ciudad, que a su vez debe volver la mirada hacia el importante rol de los ecosistemas que conforman su sistema natural, y planificar pensando en rehabilitar, proteger y preservar bosques naturales, páramos, humedales y cuencas hidrográficas ${ }^{6}$.

La perspectiva conservacionista parece ser una idea que resulta de una época en la que la transformación de la naturaleza se

6. Los bosques y los humedales mejoran la calidad del agua, generan oxígeno y retienen carbono. Además, regulan los flujos y suministros de agua, recargan los acuíferos y almacenan agua, previniendo los riesgos de desastres y la erosión de los suelos (Contraloría de Bogotá, 2005). acelera (Leal, 2002: I28). En los cerros Orientales, las dinámicas de expansión urbana, la extracción de recursos del bosque y otras formas de ocupación son las que interpelan la política conservacionista que es asumida principalmente por el estado y por algunos sectores de la sociedad civil que han introyectado el discurso ecologista. Surge la categoría de espacios o áreas protegidas mediante normativas constitucionales y procesos de planificación con enfoques de conservación que implican mayor presencia del gobierno de la ciudad para ejercer control sobre el ordenamiento y manejo, ya que la calidad y cantidad de tierras destinadas a la conservación son del dominio público. El conflicto entre lo público y lo privado comienza a reflejar las debilidades del enfoque conservacionista ortodoxo, ya que 
para conservar el estado debe adquirir predios y llevar a cabo acciones policivas para impedir la ocupación. Al hacer efectiva la retirada de habitantes del área destinada a la conservación, el estado debe sustentar la sostenibilidad de las áreas protegidas, es decir, garantizar el flujo de recursos destinados a la conservación de los ecosistemas. En este sentido, el pensamiento y la política conservacionista refuerzan el límite de la relación sociedad-naturaleza, demarcando con alambradas y vallas las áreas en donde la expansión urbana y la ocupación veredal o barrial transgreden los límites territoriales entre lo peri-urbano, lo rural y la reserva forestal. A su vez, este conservacionismo esquemático de estado niega todo espacio de experiencia y toda tradición relacionada con el campesinado, al tiempo que erige su discurso como respuesta a la expansión urbana en los bordes de la ciudad. Las prácticas estatales y distritales de la conservación introducen nociones de ilegalidad en todo proceso de ocupación que suponga la invasión del territorio reserva.

A continuación señalaré algunos hechos históricos relevantes que dan lugar a la construcción discursiva del conservacionismo y las políticas de conservación en los cerros Orientales. La conciencia de los actores distritales respecto de los servicios ambientales estratégicos que aportan los cerros a la ciudad, y entre ellos el agua, llevó a que en IgIs la administración suscribiera el acuerdo municipal No. 8 que reguló la compra o expropiación de las hoyas hidrográficas de Bogotá por parte del municipio (Universidad de los Andes-Cifa, I999). Los primeros predios adquiridos por el distrito correspondieron a las hoyas hidrográficas de los ríos San Francisco, San Agustín y San Cristóbal y las quebradas de Las Delicias y La Vieja. Se compró en total cerca de 7.000 fanegadas, lo que significó el desalojo de más de cuatro mil vecinos del lugar, un número significativo de habitantes para la época en mención (Universidad de los Andes-Cifa, 1999).

Treinta años más tarde, en 1945, la administración gestionó la compra de nuevos predios sobre los cerros para iniciar programas de reforestación en las cabeceras de los ríos San Francisco, San Cristóbal, Arzobispo y Los Rosales, con el objeto de dar respuesta a los problemas de abastecimiento de agua para la ciudad (Ibídem). De ahí se desprende otro momento significativo que fue la creación la Empresa de Acueducto y Alcantarillado de Bogotá (EAAB), que en I955 Comenzó a adquirir buena parte de los predios localizados en las laderas de los cerros Orientales con el propósito 
de protegerlos (Ibídem). En la actualidad, la EAAB posee 40\% de las I4.000 hectáreas. La ley 2a de I959, conocida también como ley de reservas, hizo que los cerros Orientales entraran en la tipología de áreas naturales por conservar. En I96I se creó la Corporación Autónoma Regional (CAR), entidad encargada del manejo ambiental de la región de Cundinamarca, que incluye a Bogotá, y que asumió el manejo ambiental de las zonas rurales de Bogotá y entre ellas, de la cuenca del río Teusacá (Mesa, 2002). Vimos cómo el gobierno distrital representado por esta recién creada autoridad ambiental impulsó las plantaciones de pinos como una forma de modernización de la economía extractiva en el bosque oriental. Como ya se dijo, la ciudad percibió ese proyecto reforestador con especies exóticas como una iniciativa de restauración ambiental que mejoró la calidad del paisaje que ofrecía el verde telón de fondo al oriente de la urbe. No obstante, el hecho que más impactó en los procesos de conservación y manejo forestal fue la aparición de la resolución 76 de 1977, mediante la cual el gobierno nacional declaró los cerros Orientales como reserva forestal protectora, de acuerdo con lo dispuesto en la ley de reservas del país. La autoridad que expidió la resolución fue el entonces Instituto Nacional de los Recursos Naturales (Inderena), hoy convertido en Ministerio de Ambiente, Vivienda y Desarrollo Territorial, que también delegó en la CAR las funciones de administración y manejo de la reserva forestal.

La resolución 76 de 1977 obedece a una nueva lógica de manejo forestal en la que sólo es posible la preservación radical del bosque y de la biodiversidad, limitando al máximo cualquier actividad humana. Con esta medida se consolidó la concepción del territorio "reserva" en oposición a las territorialidades rurales a las que hicimos referencia, y a las dinámicas de suburbanización que explicaremos más adelante. Vale decir que la resolución 76 de 1977 detuvo en cierto sentido la expansión urbana en el borde, pero desconoció los derechos de propiedad de las familias campesinas de la cuenca del río Teusacá y de otras áreas rurales cuya ocupación y tenencia de la tierra se remontaba a muchos años atrás. Los efectos de esta invisibilidad de los territorios rurales no se hicieron evidentes sino hasta finales de la década de I980, cuando las veredas del El Verjón bajo y Verjón alto experimentaron un aletargamiento en las actividades productivas como consecuencia del control ambiental. Actividades como el cultivo de papa y alverja, así como la porcicultura fueron las más afectadas por las medidas conservacionistas (Ramírez, 2003). 
Por otra parte, muchas actividades de extracción de minerales y de recursos florísticos quedaron frenadas en la cuenca del río Teusacá. En los años 1990 se sancionó la venta de musgo y quiches, y entre 1999 y 2000 se cerraron las canteras que se encontraban en el Verjón bajo. Este hecho marcó el fin de la actividad minera, al menos en la cuenca del río Teusacá (Ramírez, 2003). En la década de 1990 el distrito creó el Departamento Técnico Administrativo del Medio Ambiente (Dama) ${ }^{7}$, que se convirtió en la autoridad ambiental para la zona del perímetro urbano de Bogotá, mientras que la CAR siguió controlando la región

7. Con la reforma administrativa de 2006, el Dama se convirtió en la Secretaría Distrital de Ambiente. de Cundinamarca. Empero, la cuenca del río Teusacá, esa interfase y frontera urbano-regional, fue el escenario de yuxtaposición de competencias y poderes institucionales entre estas dos autoridades ambientales -una regional y otra urbana- que acarreó fuertes tensiones por los enfoques dados al ordenamiento ambiental de la cuenca y a los enfoques conservacionistas. Sobre este punto volveré más adelante.

Las dinámicas conservacionistas no sólo han tenido origen en la institucionalidad estatal, sino también en algunas experiencias de movilización social con intereses de reapropiación de la naturaleza en el marco de relaciones de convivencia armónica con el ambiente y de revaloración de la identidad cultural. Muchas de ellas surgieron como consecuencia de la injerencia de actores ambientalistas que directa o indirectamente han llevado a cabo proyectos de conservación en la zona. La apropiación directa en la cuenca ha sido mediante la compra o arriendo de predios por parte de grupos ambientalistas como las fundaciones Macrobosque, Parque Museo del Páramo o la experiencia agroecológica de la finca Utopía, que han propugnado a la restauración biocultural en la cuenca del río Teusacá mediante la rehabilitación de ecosistemas degradados, la recuperación de los alimentos tradicionales y de sus técnicas de producción, así como de otros aspectos relacionados con el patrimonio natural y cultural de la región. Iniciativas de tipo agroecológico como el cultivo de la quinua en los cerros Orientales son asumidas por el sujeto neorrural -personas que no son campesinas ni citadinas- y son fruto de otro régimen de construcción territorial que se focaliza en la suburbanización, como veremos a continuación. 


\section{La expansión urbana}

LA EXPANSIÓN URBANA HACIA LOS CERROS ORIENTALES ES UN FENÓMENO QUE se da desde finales del siglo diecinueve y que tiene su máxima expresión durante la segunda mitad del veinte. En la cuenca del río Teusacá la presión por ocupación y los procesos de loteo sólo comenzaron a sentirse hacia las últimas décadas, especialmente en los decenios de 1980 y 1990. Es en el borde urbano de los cerros donde este fenómeno se ha hecho presente desde mucho antes, cuando las canteras y los chircales sucedieron a las fincas de encargo y allanaron el terreno con la explotación minera. Uno de los hitos históricos correspondió al surgimiento de la zona alfarera de chircales que dio origen al entonces denominado barrio Colorado, ubicado al oriente de la carrera 7 entre las calles $40 \mathrm{y}$ 65. Posteriormente, en ese mismo sector, se desarrollaron barrios como el Mariscal Sucre, el Paraíso y la parte alta de la localidad de Chapinero (Universidad de los Andes-Cifa, 1999).

Varios hechos históricos se relacionan con la expansión de barrios urbano-populares en los cerros. Para empezar, la modernización que introdujo la industrialización en Bogotá a comienzos del siglo veinte incidió en la migración rural-urbana que aumentó conforme al incremento de las tensiones agrarias y de la violencia en los campos. La migración se convirtió en uno de los causales de la expansión acelerada de la ciudad hacia sus bordes, donde el auge minero generó una oferta de trabajo que se mantuvo hasta que los enclaves de extracción decayeron y muchos de los dueños pagaron con la tierra a los trabajadores. Así comenzó el proceso de loteo y establecimiento de los barrios urbano-populares de desarrollo progresivo. Para los años I920 había en Bogotá dieciocho barrios obreros en condiciones precarias, la mayoría localizados sobre la falda de los cerros Orientales en el denominado "Paseo Bolívar", que se extendía desde el parque de la Independencia hasta el barrio Egipto. De este modo, los cerros continuaban siendo el territorio de sectores subalternos y marginados que desde la colonia y hasta el siglo veinte conservaban fuertes rasgos indígenas. Es interesante observar el desinterés que mostraron la administración pública y la sociedad bogotana de ese entonces hacia los cerros. De ahí que el borde urbano se desarrollara relativamente al margen del gobierno distrital mediante mecanismos de autogestión comunitaria y acompañamiento por parte de diversas organizaciones no 
gubernamentales que tuvieron su mayor auge hacia la década de I960; barrios como los Laches o Pardo Rubio son beneficiarios de este tipo de iniciativas. Para esta época una nueva oleada migratoria agudizada por la violencia bipartidista de la década de I950 dinamizaría nuevos procesos de urbanización informal.

Los cerros Orientales, que hasta las primeras décadas del siglo habían permanecido subvalorados y prácticamente abandonados por la ciudad, empezaban a ser epicentro de nuevas tendencias de ocupación y urbanización opuestas a la establecida por los mencionados barrios populares de desarrollo progresivo. Esto se evidenció especialmente hacia la década de 1960 y 1970, cuando se establecieron dotaciones educativas, condominios y desarrollos de vivienda planificados que propugnaron por la revalorización del suelo en el borde del bosque oriental. En el contexto de ese nuevo desarrollo urbanístico, la administración distrital propuso a comienzos de I970, el Plan integral de desarrollo urbano de la zona oriental (Piduzob), que supuso el desalojo de parte de varios asentamientos subnormales y la legalización de los desarrollos progresivos que para la época ya se encontraran más consolidados. Uno de los proyectos más controvertidos del Piduzob fue el de la avenida de los Cerros (I972-1973), porque el gobierno distrital dispuso que los barrios en la zona de influencia del proyecto deberían desaparecer (Chaparro, 1997). En respuesta a la arremetida del estado, emergió una movilización social sin precedentes en el borde periurbano que se conoció como el Comité, pro defensa de los barrios nororientales. Este movimiento contó con el apoyo de organizaciones políticas como la Alianza Nacional Popular (Anapo), las comunidades religiosas y las juntas de acción comunal de los barrios que ahora se unían para impedir procesos de desalojo y de compra de predios.

Hasta ese momento, las dinámicas de la expansión urbana se daban especialmente hacia el borde, entrañando múltiples conflictos sociales derivados de regímenes de apropiación contradictorios tales como los asentamientos populares frente a mega proyectos urbanísticos. El fomento de la urbanización de las áreas veredales del bosque oriental apenas comenzaría en 1945, en la vereda Torca que se encontraba al norte de la ciudad. La Empresa Floresta Constructora Samper compró los predios de una gran hacienda y desarrolló el proyecto de vivienda campestre "Floresta de la Sabana”, que comenzó a construirse hacia 1957 (Cano, 2002). Entre tanto, en la cuenca del río Teusacá se presentaban hechos 
relacionados la accesibilidad como la adecuación del camino real que lleva del Verjón bajo a Choachí -comienzos de los años I920-, o la pavimentación de vías que conectaban a Bogotá con municipios de la región oriental como La Calera y Choachí, que más adelante facilitarían la suburbanización. Esto favoreció la disponibilidad de servicios de transporte y los intercambios económicos urbano-regionales ${ }^{8}$.

Para la década de 1980, las dinámicas de suburbanización del municipio de La Calera -al norte de la cuenca- comenzaron a permear el territorio del Teusacá

8. En I980 se creó la primera empresa de transporte público en la ruta Bogotá-Choachí (Ramírez, 2003).

y en especial la vereda Verjón bajo. La suburbanización, entendida como la movilidad de los sectores de mayor poder adquisitivo fuera de los límites del tejido urbano consolidado, trajo consigo una oleada de citadinos que llegaron a comprar las fincas de los campesinos de la vereda. Esto ocurrió en el contexto de revaloración de los cerros Orientales como escenario que permitió a los sectores élite de la ciudad y el país -políticos, industriales, artistas-, una inserción en espacios naturales que proporcionarían calidad ambiental y oferta de paisaje guardando la cercanía con el núcleo urbano. Una nueva tipología residencial compuesta por chalets y condominios dio origen a los desarrollos de vivienda suburbano; los nuevos desarrollos conformaron una ciudad difusa e invisible, caracterizada por la autodotación de algunos servicios públicos sin intervención del estado y por la automovilidad que va a permitir a los nuevos pobladores periurbanos la proximidad con los espacios funcionales de la ciudad central.

Un actor decisivo en el acontecer de los conflictos territoriales que entrañan la expansión suburbana y la resistencia campesina ha sido el propietario urbanizador que lotea y fragmenta la propiedad rural para el establecimiento de proyectos de vivienda, como sucedió en la cuenca hace más de veinte años. La suburbanización supone el despliegue de prácticas territoriales que sólo son identificadas por la institucionalidad distrital en relación con las restricciones de ocupación de la reserva forestal. Así, entidades como el antiguo Dama empiezan a hablar de la chaletización -tendencia a la construcción de casas quintas campestres-, en tanto es una dinámica de ocupación en los ecosistemas de bosque alto-andino. En una escala mucho más local, las relaciones de trabajo de vigilancia o servicio doméstico 
surgen con los cambios en la tenencia de la tierra del campesinado y con el establecimiento de fincas y viviendas campestres de gente de Bogotá.

Dos lógicas contrapuestas en lo relativo al uso del suelo y el modelo de ordenamiento territorial configuran y definen hoy lo rural urbano-regional en Bogotá. La primera es la expansión urbana desarrollista y la segunda conservacionista expresada en el establecimiento de áreas protegidas (Andrade, 2005). En la tendencia desarrollista, el desplazamiento de la frontera entre lo urbano y lo rural obedece en general a una dinámica que se fundamenta en la pérdida de valor de la tierra como espacio rural. La progresiva degradación del suelo hace difícil y costosa la recuperación del mismo para procesos productivos, quedando así expuestos al reemplazo de usos, favoreciendo los de tipo urbano. Este proceso de competencia de usos es además reforzado por el mercado especulativo de la tierra urbana, de forma tal que al resultar más barato el suelo rural se propician los procesos de expansión sobre el mismo. En la pérdida del valor de la tierra como espacio rural influyen las características del sistema de producción y reproducción presente en el tipo de actividades, la tecnología, la articulación al mercado, la diversificación agropecuaria, la rentabilidad y su redundancia en la estructura familiar y social (Dama, I996; Dama-Bachaqueros, 1998).

Los conflictos territoriales, sociales y culturales entre modelos de ocupación tipo condominio y las fincas campesinas ya establecidas se anclaron en torno a la tenencia de la tierra y se manifiestan en las representaciones de clase, estilos de vida e imaginarios de campo y de ciudad producidos por actores citadinos, campesinos y neorrurales. Los neorrurales son aquellos no-raizales que, a diferencia de los citadinos, llegaron a la vereda con un proyecto de vida que ha enfatizado en el "retorno a la tierra" y la sensibilidad por lo oriundo y lo ancestral, y se convierten en gestores locales de la conservación y de proyectos de producción sostenible y agroecológica de alimentos. Los citadinos son quienes desarrollan sus actividades fuera del territorio rural -trabajan en la ciudad-, pero habitan en él y terminan empleando a los habitantes locales en actividades agrícolas y no agrícolas. La desruralización que ha traído como consecuencia la inserción de la población campesina en actividades económicas informales en la ciudad -construcción, servicio doméstico, comercio informal- y en trabajos como administradores de fincas, celadores o 
empleados en chalets y condominios, ha acelerado las relaciones de dominación entre citadinos y nativos.

\section{La ruralidad en el tránsito entre la ciudad y la región}

LOS REGÍMENES DE TERRITORIALIDAD A LOS QUE HE HECHO REFERENCIA HAN evidenciado la existencia de los campesinos en los cerros, que a pesar de las referencias históricas y de la memoria local que es la narrativa que atestigua su presencia, sólo a finales de la década de 1990 se hicieron visibles para las entidades ambientales del distrito, que dan cuenta de la existencia de áreas en donde "persistían" actividades agropecuarias en minifundios como forma de uso principal del suelo (Dama, 1996). La territorialidad rural en los cerros Orientales y en otras microrregiones como la cuenca del río Tunjuelo se había dado en espacios montañosos, húmedos, escarpados, boscosos y de clima hostil. La ruralidad se había manifestado en la resiliencia de las comunidades que habían experimentado tanto la expansión urbana como las políticas conservacionistas en los cerros. Sus pobladores rurales, frecuentemente invisibilizados y discriminados por la ciudad, también se manifestaban hostiles a la ciudad pese a sus prácticas de movilidad pendular. El desconocimiento de un campesinado fruto de relaciones de aparcería y de constantes movilidades urbano-regionales también era resultado del rezago de los cerros respecto a la modernización agrícola que se proyectó hacia la sabana. La invisibilidad de escenarios como la cuenca del río Teusacá permitió que estas comunidades campesinas, marcadas por la movilidad entre las veredas y la ciudad, desplegaran un tipo de territorialidad en los cerros Orientales (Dama-Bachaqueros, I998). En la actualidad en todo el distrito, las áreas rurales campesinas forman parte de cuatro cuencas hidrográficas: del río Tunjuelo afluente del río Bogotá; del río Teusacá, también tributario del Bogotá; del río Blanco, afluente del Meta a través del Guayuriba; y del río Sumapaz que vierte al Magdalena. Estas son tierras frías y de páramo que forman parte de cuencas altas -desde los $2.700 \mathrm{~m}$ hasta los $4.000 \mathrm{~m}$ de altitud-.

La ocupación territorial tiene como antecedentes las oleadas de migrantes campesinos que finales del siglo diecinueve llegaron 
a Bogotá y que más tarde se asentaron en el Verjón bajo. La zona ofrecía tierra para el trabajo rural en fincas y haciendas y para las mencionadas actividades extractivas que sostenían el crecimiento de la ciudad (Teusacá, I997). A comienzos del siglo veinte se inició el proceso de fragmentación de la gran hacienda y la minifundización que se acompañó de la llegada de nuevas familias como los Flores, Rico, Rivera y Ricaurte. En la vereda el Verjón bajo todos los apellidos referidos remiten al discurso de la ancestralidad que en la actualidad elaboran los campesinos de los cerros, por cuanto se trata de familias que han persistido en conservar la producción agropecuaria así como sus derechos de propiedad y de herencia sobre la tierra (Teusacá, I997). Los campesinos cultivaban trigo, papa, chuguas y otros tantos productos que intercalaban con el pastoreo y las actividades extractivas de carbón y leña. Araban con yunta de bueyes a través de las pendientes montañosas y la agroforestería, que era el mecanismo para proteger los cultivos de los gélidos vientos andinos que constantemente amenazan con quemarlos.

\section{(...) antes se trabajaba con azadón y no con candela. Los encenillos nunca se tumbaban porque uno sabía que los árboles mismos cui- daban los cultivos de las inclemencias del clima. Es que aquí hacen heladas que queman los cultivos y eso es un drama para la gente. Por eso uno veía como antes la gente procuraba tener sus palos cerca de sus cultivos (...) (Cristino Bravo, 2006).}

Otra actividad muy importante para los campesinos era la venta en el comercio del camino a Monserrate. Cada fin de semana emprendían el camino por senderos que comunican con el cerro tutelar con el objeto de vender a peregrinos y turistas caldos, tamales, chocolates y otras comidas típicas y "chirrinchi”. Hacia 1929 el distrito inauguró el funicular que asciende al santuario de Monserrate, lo cual incrementó de forma sustancial la demanda de turistas e intensificó la movilidad pendular de los campesinos del Teusacá. Una de las prácticas de mayor arraigo y tradición en la cuenca del río Teusacá ha sido la producción del "chirrinchi”, aguardiente casero elaborado con técnicas artesanales de destilado en alambiques, que estuvo vigente durante la primera mitad del siglo veinte. El chirrinchi era la bebida más popular junto con la chicha hasta que en I925 el estado colombiano adquirió el monopolio de la 
producción de aguardiente ${ }^{9}$. Esto generó el cobro de impuestos, mayor control de la producción de licores y, por ende, la apertura del contrabando. En el ámbito local y regional, los cafuches o fabricantes de aguardiente clandestino se convirtieron en los más importantes traficantes hacia la

9. La ley 88 de I923, sobre lucha antialcohólica, facultó a los departamentos para prohibir la introducción, producción, comercialización y consumo de las bebidas alcohólicas que estos estimen convenientes. década de 1930, y la producción ilícita de licores en los cerros se hizo a través de viejos caminos prehispánicos y coloniales que eran desconocidos por la policía

de ese entonces. La prohibición del aguardiente de los cerros es un hito en la historia de la ilegalidad, cuya tradición oral redunda en la forma como la ciudad y el estado han interpelado al sujeto campesino del Teusacá. La ilegalidad como identificación se recrea en la historia de los cafuches, experiencia que a su vez reflexiona acerca del presente actual de tensas relaciones entre los campesinos y las instituciones ambientales del distrito por un nuevo concepto de ilegalidad, construido por la política conservacionista. Un relato legendario es el de papá Fidel, contrabandista que distribuía el licor en el barrio Egipto y de quien se dice burló los controles del resguardo -la policía- cuando ingresó a la iglesia del citado barrio un ataúd repleto de aguardiente.

\footnotetext{
(...) eso había unos barriles así de altos -un metro- y eso se echaba panela a fermentar y enseguida, a lo que ya estuviera ese guarapo bien fermentado, entonces se echaba en una olla a cocinar y se le ponía una caña al lado por donde salía el aguardiente (...) eso se acabó desde que se acabaron los antiguos. El resguardo siempre molestaba mucho por eso y los cafuchaderos eran prohibidos. Había gente que incluso dormía en el cafuche para proteger el aguardiente (...) (entrevista con José Martínez, abril de 2006).
}

Esa percepción del estado como el enemigo no se consolidaría en la memoria colectiva sino muchos años después de declarada la reserva forestal. Antes de 1977, las veredas Verjón alto y bajo se habían mantenido prácticamente invisibles a los ojos de la ciudad. Empero, entre 1965 y 1970 la apertura de dos grandes vías de penetración: la vía Bogotá-Choachí -al sur de la cuenca- y la de Bogotá-La Calera -al norte- significaron un acelerado proceso de descampesinización y de definitiva inserción urbana. Entre tanto, la tradición extractiva en los cerros daba un vuelco con los proyectos de aprovechamiento forestal a gran escala, como el 
establecimiento de las plantaciones de pino que los campesinos se vieron obligados a sembrar en gran parte de la cuenca. La economía agraria sufrió también una serie de transformaciones cuyos efectos ambientales hoy son determinantes en la problemática ambiental local y regional. Una de ellas es consecuencia de la revolución verde ${ }^{10}$ que en el territorio fomentó el modelo de monocultivos masivos como la papa, muy dependientes de agroquímicos, en detrimento de la cobertura vegetal que se redujo con la ampliación de áreas cultivables, del suelo y de las fuentes hídricas que empezaron a degradarse y a contaminarse.

El desarrollo de monocultivos a gran escala obedeció a la ne-

IO. Con ese nombre se conoce al periodo comprendido entre la década de I960 y I970, cuando el auge de la agroquímica y la mecanización agraria introdujo cambios sustanciales en los modos de producción en numerosas zonas rurales del mundo. Esta transferencia tecnológica trajo consigo un aumento espectacular de la productividad agrícola pero a costa de la dependencia de la industria agroquímica. cesidad creciente de abastecimiento alimentario para la ciudad. Nuevas generaciones campesinas hicieron sus fortunas con el monocultivo de la papa, y eso les llevó a aumentar los límites de su propiedad mediante la compra de predios vecinos. Aunque existen pocos medianos y grandes propietarios dedicados al cultivo de la papa, que además son de origen campesino y nacidos en la cuenca, la presencia de grandes extensiones destinadas a esas siembras evidencia cambios en la tenencia de la tierra y las relaciones de trabajo entre propietarios ausentes y trabajadores locales. Para las familias que administran los predios de los paperos y las que cuidan los chalets, estas actividades ocurren en el marco de una inminente inserción urbana subordinada, como consecuencia de la pérdida de la agricultura de subsistencia, bien sea por la expansión de la papa o por las restricciones derivadas de la política conservacionista.

La modernización del cultivo de la papa ha afectado los ecosistemas de páramo y aceleró la pérdida de técnicas de producción agroforestales y basadas en el policultivo. En los últimos diez años los monocultivos de relativa extensión les han conferido a los campesinos un nuevo estatus de ilegalidad, ya que de acuerdo con la norma ellos se encuentran dentro de la reserva forestal y algunos la habitan en calidad de invasores y depredadores de la misma. Sin duda, el momento preponderante en la historia de marginación e ilegalidad del área rural sobrevino con la declaratoria de los cerros y la cuenca del río Teusacá como "reserva forestal", que desconoció la territorialidad campesina. 
En adelante, el límite ciudad-reserva sería rígido, y es en virtud de la expansión urbana y no de las formas de territorialidad rural que los gobiernos de la ciudad empezaron a desarrollar políticas, planes y programas de protección de los cerros. El fenómeno de suburbanización incidió también en una mayor presencia institucional del distrito a partir de la cual los gobiernos se percataron de la existencia de pobladores que se identificaban a sí mismos como campesinos.

Hoy el esquema de apropiación territorial de lo rural en los cerros Orientales tiene como característica la dispersión espacial y la baja densidad poblacional, la mínima unidad es la finca campesina o minifundio con una extensión inferior a las 20 hectáreas. Las unidades agrícolas familiares que la habitan y la trabajan mantienen una vida de aldea dispersa y veredal que se encuentra distribuida entre los 2.750 y $2.800 \mathrm{msnm}$ (Ramírez, 2005). Los núcleos de habitación y las relaciones de propiedad privilegian la agricultura y el pastoreo hacia las partes altas donde se encuentran los nacederos de agua y las quebradas que sirven para el riego de los cultivos y el consumo humano. Hay sin embargo conciencia de la necesidad de conservar el subpáramo del cual depende la vida de las gentes que viven más abajo, donde predomina la agricultura parcelada. Entre las principales actividades asociadas a la subsistencia están la ganadería, la agricultura de la papa y la porcicultura (Mesa et al., 2005). Con respecto a la agricultura, vale señalar la importancia del policultivo que alberga diversas especies de papa junto con otros tubérculos de altura como el cubio, las hibias y las chuguas. Los neorrurales que llegaron con la suburbanización de la década de 1990 incentivaron a algunas familias campesinas para que incluyeran el amaranto y la quinua dentro de sus cultivos. Campesinos y neorrurales han introducido la idea de la producción orgánica y limpia como sustento de su territorialidad y su identidad, y las instituciones distritales no han sido ajenas a estos discursos; todo lo contrario, las alcaldías locales de Bogotá que tienen jurisdicción en zonas rurales han promovido estas prácticas, al introducirlas en la asistencia agropecuaria que brindan a los campesinos.

El que la población campesina se inscriba dentro del complejo de transiciones y gradientes entre lo rural y lo urbano supone cierta dificultad para establecer tipologías precisas que permitan caracterizar a un grupo social que no encaja del todo en las conceptualizaciones estables o fijas del campesinado (Tocancipá-Falla, 2005). 
Lo que caracteriza a los campesinos de los cerros es el discurrir continuo entre un contexto de pueblos y municipios de la zona oriental y la proximidad con la ciudad de Bogotá. Estos pobladores fronterizos han desarrollado ingentes estrategias para moverse entre dos mundos a partir de sus intensos trayectos e itinerarios, como respuesta a las necesidades históricas de abastecimiento de recursos naturales y alimentos y la también histórica funcionalidad de un territorio "bisagra" que permitía la conexión entre Bogotá y los municipios del oriente cundinamarqués. Las relaciones urbano-regionales en que está inmerso el campesino de los cerros se caracterizan por el efecto polarizante de Bogotá que se refleja en un proceso de descomposición o disolución de la forma rural (Dama-Bachaqueros, 1998). Se trata de una dialéctica de disolución-reproducción que se debate entre un proceso de fortalecimiento de la cultura campesina y un proceso de “descampesinización” (Shanin, I980: I4). Esa descomposición del sistema campesino se refleja en la ruptura de la familia extensa como unidad básica de la organización económica y social. Sin la familia y los derechos de propiedad que otorga la herencia en la tenencia de la tierra se verá también afectado el uso agrícola como principal fuente de sustento, a consecuencia de la inmensa presión urbana (Shanin, 1980).

Pese a que la movilidad como referente de construcción territorial hace difusa la delimitación de zonas rurales y gente campesina, son estas prácticas las que les dan una experiencia cognitiva de su relación con la ciudad y la región. Las historias de venta de leña y carbón, los mercados al aire libre en los barrios populares, la presencia dominante del propietario de la finca o el chalet y el ejercicio policivo de los funcionarios de las instituciones ambientales, son todos referentes de la experiencia y la conciencia históricamente situada de estos pobladores rurales. Inciden por lo tanto en la subjetivación del campesino de los cerros Orientales que elabora su memoria y su tradición como una herramienta para la acción colectiva y que se materializa en la construcción del proyecto de ruralidad en Bogotá. Al respecto, es pertinente revisar la política de ruralidad en Bogotá, aunque por la amplitud de la materia la dejaré apenas esbozada. Por el momento, lo interesante es analizar esta acción colectiva de la ruralidad como una lucha por el rescate del lugar de estos pobladores, que han pasado de ser esos habitantes invisibles e intersticiales para definirse como grupo social y económico en 
el haz de relaciones que plantean la encrucijada y el conflicto entre los regímenes de apropiación que hoy están en juego. Esta aseveración concuerda con la propuesta de Eric Wolf de analizar el campesinado en términos de relaciones estructurales y no de un contenido particular (Wolf, I955, citado en Tocancipá-Falla, 2005: 15).

La ruralidad de los cerros Orientales y en especial la de la gente del Teusacá es un buen caso para pensar en la cuestión de la identidad campesina. Esta es una identidad que siempre se refiere a la multiplicidad de relaciones territoriales en las que se mueve y que vistas a lo largo del tiempo conlleva la pregunta por la existencia de los campesinos de Bogotá como grupo poblacional. El conglomerado de juntas de acción comunal y de organizaciones de base ha optado por autodenominarse como pequeños productores. Esta categoría, que tiene su raigambre en el minifundio, sugiere que mientras la producción agropecuaria siga siendo desarrollada por unidades de tipo familiar con el objeto de asegurar ciclo a ciclo la reproducción de sus condiciones de vida y trabajo, se podrán seguir evidenciando dinámicas de resistencia a la descomposición del campesinado (Machado y Torres, 1987). Dinámicas que no son solamente relevantes en las formas de uso del suelo, sino también en las narrativas que elabora este sector poblacional, articulado a una heterogénea movilización social conformada principalmente por habitantes populares de los cerros, quienes interpelan con sus diferentes formas de ocupación la política conservacionista institucional. Así mismo, ponen en evidencia el poder de algunos sectores hegemónicos con intereses en los cerros y que emplean sus influencias para pasar por alto las restricciones y desarrollar proyectos de expansión urbana.

\section{CONCEPCIONES TERRITORIALES EN CONFLICTO}

OS HECHOS QUE DETALLARÉ EN LOS AÑOS POSTERIORES A I977 ENTRAÑAN la agudización del conflicto territorial avivado por el entrecruce de los regímenes de construcción territorial en los cerros Orientales y, en particular, la cuenca del río Teusacá. En síntesis, un conservacionismo a ultranza que reforzó el límite sociedadnaturaleza justo cuando la expansión urbana había llegado a su 
punto culminante y la marginalidad campesina era evidente. La década de 1990 significó para el área rural fuertes tensiones con las administraciones distritales y con la sociedad citadina que empieza a penetrar en la cuenca del río Teusacá. Es un periodo en el que los procesos de des-ruralización y suburbanización se acentúan. En el primer caso, intervienen el aletargamiento de la producción agrícola derivada de las restricciones conservacionistas, la suburbanización y la insostenibilidad de los nuevos modos de producción. La progresiva degradación del suelo hace cada vez más difícil y costosa la recuperación del mismo para procesos productivos, quedando así expuestos su reemplazo por usos de tipo urbano. Por otra parte, el mercado especulativo de la tierra estimula el corrimiento del borde y la expansión de la ciudad.

Por otra parte, los campesinos, percatados del bajo desarrollo que ha tenido la cuenca en términos de redes y estructuras, equipamientos e inclusión social, fortalecen sus juntas de acción comunal y demandan al estado la creación de una infraestructura de servicios de la cual han sido excluidos por encontrarse dentro de la reserva. Su hostilidad hacia la ciudad y los pobladores urbanos ha ido en aumento desde que el estado los convirtió en poseedores ilegales. Sólo gracias al esfuerzo organizativo y a la intervención de algún actor político lograron que en 1989 la Empresa de Energía de Bogotá les instalara los primeros postes para la prestación del servicio de energía eléctrica en el Verjón bajo (Teusacá, 1997). Este hecho tuvo efectos contradictorios: de una parte contribuyó a disminuir el consumo de leña y redujo la presión sobre el bosque, pero sentó las bases para la suburbanización de la cuenca. Es entonces cuando la comunidad campesina comienza a identificar a los nuevos actores citadinos como "los ricos de la ciudad que vienen a desalojar al campesino" y se refuerza su hostilidad hacia los extraños.

Uno aquí ya no puede hacer nada. No le dejan sembrar sus labranzas, no le dejan construir casas pa' los hijos y todo que porque esto es una reserva (...) ahora vaya mire usted las casas de los ricos que viven aquí. Parecen mansiones. Ellos tienen sus carros, trabajan en la ciudad y nadie les dice nada por vivir aquí. El campesino en cambio es perseguido (...) nosotros creemos que todo esto no es más que una jugada del gobierno y de lo ricos para quitarnos la tierra y quedarse con todo (...) esto está reservado, pero para otros (...) (entrevista con Fabio Moreno, junio de 2006). 
Hacia finales de la década de I990, las condiciones de marginalidad del territorio rural habían tocado fondo. Frente a las restricciones y sanciones impuestas por la Corporación Autónoma Regional (CAR) y frente a la oferta de suelo por parte de loteadores, muchas familias decidieron vender y trasladarse a Bogotá. Los pocos campesinos que aún desarrollan actividades productivas en sus propias fincas hoy se han visto abocados a tomar las partes más altas de la cuenca en virtud de la presión por ocupación ejercida por los citadinos y la suburbanización. Este confinamiento hacia las áreas de subpáramo y nacimientos de quebradas ha acrecentado los problemas ambientales causados por actividades como el monocultivo de la papa y el pastoreo. Actividades como estas hoy representan un riesgo para las fuentes hídricas y los ecosistemas de subpáramo.

Pero los conflictos no sólo obedecen a las tendencias de suburbanización frente a ruralidad. La acentuada posición general de subordinación de las unidades sociales campesinas dentro de redes más amplias de dominación económica, especialmente con la configuración del territorio “despensa”, generó una crisis en las dinámicas de ruralidad descritas. Buena parte de los campesinos habitantes de la cuenca hoy han desplegado una praxis extractivista y utilitarista sobre el territorio. Así, la demanda de recursos forestales y la tecnificación agrícola terminaron por debilitar las prácticas sostenibles que habrían representado soluciones a los retos de conservación de la naturaleza sin que esto conllevara desconocer el valor de hábitats creados por los campesinos. Estas prácticas se pueden percibir en el aumento de la conciencia individual sobre la colectiva y la visión instrumental sobre la naturaleza. Muchas veces los conflictos vecinales y familiares surgen de la tenencia de la tierra y del aprovechamiento de recursos naturales. De ahí se deriva, en parte, la atomización del tejido social que promueve el liderazgo local. Incluso, la hostilidad manifiesta de algunos campesinos puede ser consecuencia del deficiente tejido social y cohesión que da más seguridad y capacidad de interacción a los pobladores entre ellos mismos y con los foráneos.

Todo lo anterior implica una paradoja que deriva del conflicto entre área rural, expansión urbana y reserva forestal. El desplazamiento de la frontera entre lo urbano y rural, que es la principal amenaza para la conservación del bosque, es consecuencia de la pérdida de valor de la tierra que a su vez es resultado de las 
mencionadas restricciones legales conservacionistas que aletargaron la producción agrícola. Las contradicciones inherentes a la frontera han llegado a su mayor. Cuanto más rígidos son los procesos conservacionistas más afectaciones se evidencian en el bosque oriental y más resistencia local ofrecen las áreas rurales. Este último fenómeno comienza a darse con la valoración relativa del espacio rural dentro del contexto internacional del derecho de los pueblos al desarrollo local y al ambiente. En el distrito, la década de 2000 supone el fortalecimiento de una política de ruralidad en virtud de las características ecológicas, socioeconómicas y socioculturales particulares de los territorios campesinos, de su potencial ecoturístico y de reserva hídrica, su extensa geografía y su importancia regional. También adquiere valor su uso espacial, económico y agro-silvo-pastoril del territorio y el hecho que sus habitantes pertenezcan a comunidades pequeñas asociados de forma peculiar con su entorno natural.

Al igual que el discurso de la conservación, el de ruralidad plantea conflictos entre instituciones de carácter regional como la Corporación Autónoma Regional de Cundinamarca, el Departamento del Medio Ambiente y las alcaldías locales. Mientras unos entes ejercen funciones policivas de cierre de porquerizas y de multas, otros brindan el servicio de asistencia técnica agropecuaria, que comenzó funcionar a finales de la década de I990. En 2000 la ciudad adoptó el plan de ordenamiento territorial del distrito capital y formuló los lineamientos de manejo de los cerros. Al año siguiente, el Ministerio del Medio Ambiente, la CAR y el entonces Departamento Administrativo del Medio Ambiente crearon una comisión conjunta con el objeto de definir el ordenamiento y manejo del área. En 2002, las tres entidades acordaron la formulación y reglamentación del Plan de ordenamiento y manejo de los cerros Orientales (Pomco) enfocado a garantizar los procesos de conservación de la reserva, la rehabilitación y la generación de espacio público natural para la ciudad. Ese plan incluyó un acucioso proceso participativo y de consulta con las comunidades, y especialmente con los campesinos de la cuenca del río Teusacá. Empero, la historia de la intervención institucional en los cerros Orientales es tan conflictiva como las dinámicas territoriales que han configurado el paisaje, y las tensiones de poder y los conflictos por la competencia y el control sobre los cerros ha caracterizado las relaciones entre la CAR y el Dama. Este conflicto de competencias no permitió que el Pomco 
se reglamentara y tendrían que pasar cuatro años para que la Corporación Autónoma Regional propusiera un nuevo plan de manejo para los cerros y sus áreas rurales.

En abril de 2006 esa entidad publicó la resolución II4I, que reglamentó un nuevo plan de manejo que resultó ser más incendiario que todos los anteriores en tanto propone consolidar el uso forestal protector como uso principal y prohibir los usos agropecuarios, industriales, urbanísticos, mineros y de disposición de residuos sólidos. No obstante, plantea superar su esencia confrontadora de los múltiples estratos de territorialidad ya existentes, aludiendo tecnocráticamente a los "usos condicionados", para permitir el aprovechamiento del paisaje, la educación ambiental, la recreación pasiva y la instalación de infraestructura de servicios y de seguridad. La puesta en práctica de proyectos en esa línea, y concretamente la experiencia a que haré referencia, contradice las concepciones fragmentarias y ahistóricas de la política conservacionista.

\section{RECORRER HITOS PARA HILVANAR HISTORIAS}

\footnotetext{
$\AA_{\text {t }}^{N}$

II. Esta planta es una especie de bambú de alta montaña, con tallos como cañas. A diferencia de la guadua, los tallos son sólidos por dentro.
}

NTES DE CONCLUIR, ESTA REFLEXIÓN TIENE QUE VER CON LA MANERA COMO SE entrelazan experiencias vitales individuales como partes constitutivas de la naturaleza, con vivencias sociales, para dar sentido y para colmar de significado las relaciones entre las personas y el entorno (Ardila, 2006). Una plantación forestal o una vivienda campesina tradicional hecha aún con chusques ${ }^{11}$ en lo alto de una ladera se nos presentan ahora como dos metáforas relativas a las territorialidades que alberga el paisaje de los cerros Orientales. Ambos son instrumentos de conocimiento y marcadores

de la memoria histórica que remiten a experiencias y sucesos que dan cuenta de tales territorialidades y de sus relaciones especialmente conflictivas. Así como la pequeña finca con cultivos para el autoconsumo es marcador de la territorialidad rural, las áreas de subpáramo, los chalets o las haciendas de encargo también pueden relacionarse con la construcción de territoritorialidades de la conservación o de la suburbanización. La comprensión histórica, social y cultural de cómo es que estas metáforas devienen 
metáforas tiene que ver con lo que este ensayo expuso en su primera parte sobre la construcción de al menos tres tipos de territorialidad.

Pensar los entrecruces entre la formas de territorialidad que coexisten y se reproducen en el espacio implica derribar las barreras rígidas que oponen la naturaleza a la sociedad. Barreras que se materializan en ideas políticas normadas que sólo apuntan a exacerbar la realidad compleja y contingente de los territorios intersticiales. En mi opinión, esto llevaría a encontrar lugares comunes entre los procesos de suburbanización, conservación y ruralización. A esto agregaría que la resistencia de los territorios rurales y la transgresión de la ciudad entrañan conflictos de clase que también emergen de las relaciones interculturales entre citadinos neorrurales y campesinos. La reflexión antropológica de este ensayo consiste entonces en entender que cultura y naturaleza se crean y recrean mutuamente, y que la cultura debe ser vista como confrontación y diálogo, dada la realidad intercultural y de conflicto territorial que he ilustrado. Esta reflexión surge de una experiencia de identificación participativa de referentes territoriales que los actores campesinos y no-campesinos consideraron relevantes como hitos o huellas claves para entender la histórica de la cuenca del río Teusacá, en tanto que allí la memoria ha construido y articulado narrativas relativas a las territorialidades.

En 2006 la alcaldía de la localidad de Chapinero priorizó un proyecto de desarrollo local, a propósito de las presiones por el desarrollo urbano y la conservación del bosque oriental de su jurisdicción. Una porción de la cuenca media y baja del río Teusacá en donde se encuentra la vereda el Verjón bajo fue objeto de un estudio paisajístico y sociocultural orientado a evaluar la viabilidad de construcción de un parque ecoturístico en la zona. La socialización del proyecto con los diferentes complejos poblacionales empezó mal, precisamente desde el título del mismo: “¿Construcción? ¿Parque?”. Este lenguaje significaba, tanto para campesinos como para citadinos, que el proyecto no era más que una argucia del distrito en busca de una estrategia efectiva de expropiación. Pese a los problemas de formulación, lo que este proyecto buscaba era identificar alternativas de desarrollo local por la vía del turismo de naturaleza, sin que ello riñera con la política conservacionista. Cabe agregar que el proyecto tenía un enfoque diferencial ya que privilegiaba la participación y los 
beneficios para la comunidad campesina, que en este caso era el sector más vulnerable a las presiones de la conservación y de la expansión urbana.

Mi interés no es hablar de los resultados de ese proyecto. Me centraré en describir la experiencia de identificación de referentes histórico-culturales en la cuenca media del río Teusacá y la forma como los actores locales se involucraron en este proceso. Lo primero que hicimos fue dejar de lado la noción de "parque" y hablar de rutas o senderos que articularan hitos ecológicos e histórico-culturales. Mediante una serie de talleres en los que se emplearon mapas parlantes, obtuvimos información preliminar acerca de referentes de importancia paisajística tales como altos de colinas, afloramientos rocosos, miradores naturales, riscos y desfiladeros. Los referentes hídricos evidenciaban la importancia de varios nacederos, lagos, cascadas y quebradas, incluyendo el propio río Teusacá, en los procesos ecológicos, sociales y culturales. Una categoría de referentes de tipo biótico eran los bosques plantados de pino y las áreas de transición entre bosque alto-andino y subpáramo cubiertas de frailejones y zarcillejos, o las rondas de quebrada sembradas con alisos. Estas aparecían asociadas a la presencia y al discurso ecológico de los campesinos en la cuenca, al igual que las huertas tradicionales campesinas y los proyectos agroecológicos en los cuales se rescataban variedades de papa que la tecnificación agrícola había desaparecido. Por otra pare, los caminos prehispánicos y reales hacia Choachí, las casas de antiguas haciendas y las viviendas campesinas más antiguas aparecían como referentes de la tradición oral de los campesinos del Teusacá.

Luego de este primer ejercicio, identificamos una red de senderos existentes que pudieran hilvanar un recorrido por cada uno de estos referentes. En la cuenca del río Teusacá ya existían experiencias de caminantes que tenían un amplio conocimiento de todas las rutas, aunque no la comprensión de la importancia ecológica, social y cultural de las quebradas, las huertas o los bosques nativos. Las personas que finalmente se involucraron en el proceso de identificación de hitos eco-culturales hacían parte de organizaciones que daban cuenta de la complejidad de actores sociales. Había miembros de la junta de acción comunal de la vereda; un grupo de señoras que hacían parte de la red de mujeres campesinas del Verjón; una familia campesina de agricultores de papa orgánica y comerciantes de quesos en Monserrate; 
y una pareja de arrendatarios de un chalet que habían llegado al Teusacá hacía unos años y que habían montado un proyecto de agricultura orgánica con base en la siembra de quinua para el autoconsumo y la comercialización. Junto con ellos estuvo la fundación Parque museo del páramo, una ONG que abogaba por la conservación de las laderas altas de la cuenca, ya que su líder era propietario de terrenos en donde no se podía construir sino restaurar y conservar. Igualmente, había algunos propietarios de condominios y chalets que estaban interesados en conocer mejor el entorno en el cual habitaban pero que poco habían explorado porque la mayor parte de sus actividades las desarrollaban en Bogotá.

La identificación de las rutas fue posible gracias al caminante Alfonso Molano, avezado en el reconocimiento de sendas relevantes en los planes de caminata que él y otros citadinos y neorrurales habitantes de la cuenca habían ideado como oferta de servicios a personas que venían de la ciudad y que anhelaban el contacto con entornos naturales. Pero por otra parte estaba el señor Miguel Pineda, campesino que había logrado establecer un proyecto agroecológico que aseguraba sustento a su familia y que, a su entender, era "ejemplo para los paperos que envenenaban las laderas de la cuenca con puros agroquímicos". Don Miguel Pineda era propietario de un predio cerca del alto de la Cruz; se trataba de un bosque enano sobre los $3.000 \mathrm{msnm}$ de cuyos colchones de agua brotaban varios hilos que luego se volvían quebradas e irrigaban los cultivos de la gente de abajo. Por esto don Miguel insistía en la necesidad de conservar ese predio tal como estaba; tal conservación incluía dejar intacta la desvencijada casa paterna en que él se crió, con sus chusques y adobes.

Hicimos cuatro recorridos que nos permitieron documentar los referentes que habían sido señalados en los mapas parlantes. A partir de allí propusimos dos rutas: la primera comprendía la zona de ladera y la cuchilla o divisoria de aguas que marca el límite entre el área de borde urbano de los cerros Orientales que aparecen como telón de fondo de Bogotá, y la zona del Teusacá. Desde el punto de vista ecológico, este corredor marca la transición entre los ecosistemas de bosque alto-andino y subpáramo. Desde el punto de vista histórico y ambiental se presenta como un interesante conector de la vereda con la ciudad a partir de los caminos emprendidos por los campesinos para bajar a ella, y de los miradores que proporcionaban una vista privilegiada de 
la ciudad. La segunda ruta iba desde un tramo del camino real entre Monserrate y Choachí hacia el alto de la Cruz que hace de frontera entre la cuenca del río Teusacá y el municipio de Choachí. A diferencia de la primera ruta, este recorrido permite reconocer a la cuenca en sus relaciones con la zona oriental.

Cada ruta poseía unos itinerarios dados por la presencia de vegetación nativa, bosques plantados, lugares de la memoria local, casas, quebradas, miradores, montes, rondas de quebrada, desfiladeros, nacederos y huertas orgánicas -algunas introducidas por los llamados neorrurales, otras tradicionales de los campesinos y otras como fruto de la asistencia técnica agropecuaria que brinda la alcaldía local de Chapinero-. Los patrimonios gastronómicos de los campesinos también fueron propuestos por la red de mujeres, organización que asumiría la preparación de platos típicos como el cocido a base de diversos tubérculos y la venta del popular chirrinchi, especial para atenuar el frío de la zona. A su vez, los jóvenes campesinos del colegio el Verjón bajo avizoraban las actividades de guianza turística por los caminos como una actividad que podría complementar la necesidad de ingresos y menguar el éxodo a la ciudad.

En julio de 2006 algunos funcionarios de la alcaldía local de Chapinero, del entonces Instituto Distrital de Cultura y Turismo, de la Corporación Autónoma Regional de Cundinamarca y de otras entidades participaron de los recorridos en compañía de jóvenes campesinos que habían asumido la tarea de guías. Los visitantes conocieron los proyectos de agricultura orgánica y las prácticas de conservación de las familias campesinas así como el influjo de una nueva ruralidad y de las tendencias conservacionistas que habían introyectado algunos citadinos que habían llegado en las últimas décadas. Al finalizar los recorridos y degustar la gastronomía que ofreció la red de mujeres, muchos de estos funcionarios quedaron maravillados de la riqueza natural y cultural que había tan cerca de Bogotá. Sin embargo, los tejemanejes burocráticos y administrativos en la localidad no permitieron la continuidad de este proyecto. No hubo fases posteriores que consolidaran la posibilidad de conjuntar patrimonios naturales y culturales, pese a que había una heterogénea base local -citadinos, neorrurales, campesinos, ambientalistas- que habría podido jalonar esta iniciativa. Quizás el conflicto de las territorialidades preexistentes siga siendo más fuerte que la necesidad de pensar en términos relacionales articulando siempre equidad social 


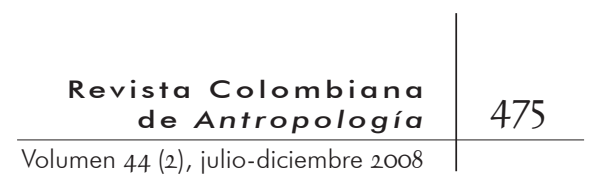

con sostenibilidad ambiental y estas dos con sustentabilidad económica. La experiencia de la cual parte mi reflexión pone en evidencia una vez más el papel que tiene el conocimiento local codificado en cosas concretas, que además de revelar historias también constituyen potenciales eco-culturales, educativos, científicos y económicos para pensar en el ordenamiento territorial de los cerros Orientales.

\section{Conclusiones}

L CHOQUE ENTRE DIFERENTES SENTIDOS DE TERRITORIALIDAD ES PARA LA - etnografía y la historia de las relaciones entre cultura y entorno - una forma de ver cómo se establecen las relaciones de poder en escenarios concretos. Así, los regímenes de territorialidad en los cerros Orientales indican que no se trata de un simple contorno o telón de fondo para Bogotá, sino que son el teatro de múltiples historias que si bien están asociadas al desarrollo de la ciudad no pueden verse únicamente a partir de ella. Son un territorio de frontera por cuanto sus límites difusos entre ciudad y bosque, entre espacios rurales y urbanos evidencian las transgresiones del desarrollo de la metrópoli y las resistencias de la gente campesina, cuya historia de ocupación transgrede, a su vez, el ideal de conservación ecológica del bosque oriental. En la cotidianidad de los actores que habitan los cerros existen elementos que permiten pensar este paisaje en toda su complejidad, y por ello vale la pena explorar la propuesta de su ordenamiento desde la experiencia situada de estos actores, ya sea que ellos se encuentren en los barrios populares, en los condominios de estrato alto o en las veredas campesinas.

El conflicto entre lo público y lo privado demuestra las debilidades del enfoque conservacionista ortodoxo. Para conservar, el estado debe adquirir y expulsar a la gente. La conservación de la diversidad ha adoptado formas diferentes en los países desarrollados y en los países en desarrollo, pero hay al menos un elemento común que es poner a la humanidad en el centro de la conservación. Una verdadera ecología del bienestar debe interesarse por la calidad ambiental y el conservacionismo, sin pasar por alto cuestiones sociales tales como los derechos democráticos, el acceso equitativo a los recursos naturales, los 
aspectos recreativos y las necesidades espirituales y psicológicas de las personas. Las políticas de conservación deben abocarse aún más a comprender el carácter dinámico y, por tanto, cambiante de las sociedades y sus entornos. En contravía de esto, la mencionada resolución II4I que reglamenta el último plan de ordenamiento de los cerros Orientales expedido por la CAR planea una lenta pero progresiva adquisición de predios campesinos a partir de restricciones que dificultan su permanencia en el territorio. Sin embargo, promueve la regulación de actividades ecoturísticas como una forma de aprovechamiento del paisaje. Precisamente, la desterritorialización que supone esta visión conservacionista va en contravía de la idea del paisaje que aquí he expuesto y que al hacerlo, pretende desconocer el urdido de realidades que han hecho de los cerros Orientales lo que verdaderamente son. Por otra parte, considero que los espacios de transición rural-urbana descritos se encuentran en un momento histórico clave, en el cual las funciones estrictamente productivas -obtención de alimentos y de otros productos de la tierra-, aunque importantes, empiezan a dar paso a actividades más vinculadas al consumo de naturaleza o de paisaje (Saurí y Boada, 2006). Esta no pretende ser ni mucho menos la propuesta única para la Bogotá rural que sigue siendo invisible en el contexto del ordenamiento “ciudad-región”. Simplemente debe mirarse como una alternativa o un complemento dentro de la exigencia de derechos económicos, sociales y culturales en el horizonte de expectativas que vislumbran los espacios rurales del distrito. El problema del desarrollo rural de Bogotá tiene como aspectos más apremiantes la seguridad alimentaria, el comercio justo de los productos agrícolas que compiten en condiciones desiguales con grandes empresas comercializadoras de alimentos, la pésima educación que reciben los niños y las niñas campesinas, tanto en términos de infraestructuras como de currículos; y aspectos de accesibilidad y conectividad que demuestran la precariedad de las vías y del sistema de transporte para una población altamente móvil.

En los últimos años las presiones de ocupación en los cerros Orientales han dado lugar a la agregación de múltiples movimientos ambientalistas, de barrios populares y campesinos, entre otros. La Mesa de Cerros ha sido esa instancia que ha permitido la confluencia de estos sectores de la sociedad civil que optan por la propuesta de unos cerros vividos y cuidados frente a las políticas de conservación que se ensañan con estos pobladores y en cambio sí se han hecho los de la vista gorda a las preten- 
siones de urbanizaciones de estratos cinco y seis. Las múltiples resoluciones relacionadas con la conservación, muchas de ellas derogadas, son fiel reflejo de un contexto político institucional débil a la hora de sentar las bases del ordenamiento territorial.

Todo lo anterior nos plantea que en la medida en que estos procesos sociales propongan y generen cambios en las relaciones de poder que han configurado comportamientos y normas de territorialidad, la encrucijada y el conflicto por el cual atraviesan los cerros tendrán que cambiar. Esto no es tarea fácil y en lo que respecta a la producción de conocimiento especializado corresponderá a otros estudios de la historia ambiental hacer análisis un poco más detallados de las formaciones discursivas que entrañan las políticas de la conservación de los cerros Orientales durante, por lo menos, los últimos treinta años. Así mismo, su efecto en las transformaciones territoriales que determinaron los conflictos ecológicos, sociales y culturales en los cerros. Resalto la importancia de realizar estudios acerca de las situaciones históricas de conflicto en espacios geográficos y paisajes de frontera. Finalmente, invoco esta categoría porque el estudio de la frontera en historia ambiental se relaciona con el retroceso del bosque (Sedrez, 2002). Una frontera no es una línea que marca el límite entre uno y otro orden, sino un área de permanente tensión entre la expansión y el límite (Casstronovo, 2003) y esa es la historia de apropiación, encrucijada y conflicto en los cerros Orientales.

\section{BibliogRAFÍA}

Amérigo María y González Antonio. i999. "Actitudes hacia el medio ambiente y conducta ecológica”.Psicothema. II (I).

Andrade, Germán. 2005. "La continuidad de los parques". En Claudia Mesa et al. (eds.). Ciudad, región y áreas protegidas. Manejo territorial y participativo. Fescol. Bogotá.

Álvarez, Manuela. I999. "Prácticas espaciales y regímenes de construcción de la ciudad de Tumaco". En Juana Camacho y Eduardo Restrepo (eds.). De montes, ríos y ciudades. Territorios e identidades de la gente negra en Colombia. Fundación Natura-Ecofondo-Ican. Bogotá.

Álvarez, RAúL. 2004. "Ideologización del espacio en doña Perfecta y aves sin nido: la oposición campo-ciudad. Decimonónica. I (I). www. decimonónica.org/VOL_I.I/Alvarez_VI.I.pdf 
Ardila, Gerardo. 2006. “Cultura y desarrollo territorial”. Conferencia para el diplomado gestión de procesos culturales y construcción de lo público. Instituto Distrital de Cultura y Turismo. Bogotá.

BARSKI, ANDRÉs. 2005. "El peri urbano productivo, un espacio en constante transformación. Introducción al estado del debate, con referencias al caso de Buenos Aires”. Revista electrónica Scripta Nova (geografía y ciencias sociales). IX (I94) (36).

Cano, Beatriz. 2002. "Caracterización de los sistemas de alteridad de la localidad de Usaquén. Recorrido Floresta de la Sabana”. Informe final Plan de ordenamiento y manejo de los cerros Orientales (Pomco). Departamento Administrativo del Medio Ambiente (Dama). Bogotá.

Casstronovo, Russ. 2003. "Narrativas comprometidas a lo largo de la frontera: narrativa Mason-Dixon, la resistencia y la hegemonía”. En Alejandro Grimson (comp.). Teoría de la frontera. Los límites de la política cultural. Gedisa. México.

Corporación Autónoma Regional de Cundinamarca (CAR). I999. "Estudio plan integral de ordenación y manejo de la cuenca del río Teusacá”. Bogotá.

ChAPARro, Jairo et al. 1997. Un siglo habitando los cerros. Vidas y milagros en el cerro del Cable. Alcaldía Local de Chapinero. Bogotá.

Departamento Administrativo del Medio Ambiente (Dama). I996. Diagnóstico de áreas rurales de Bogotá. Dama. Bogotá.

Dama-Fundación Estación Ecológica Bachaqueros. ig98. Plan de manejo de ecosistemas estratégicos para las áreas rurales del Distrito Capital. Dama. Bogotá.

Haraway, Donna. I99I. "Conocimientos situados: la cuestión científica en el feminismo y el privilegio de la perspectiva parcial”. En Ciencia, cyborgs y mujeres. Barcelona.

Herrera, Alexander. I999. "Patrones de asentamiento y cambios en las estrategias de ocupación en la cuenca sur del río Yanamayo”. Ponencia presentada al XII congreso peruano del hombre y la cultura andina realizado en Huamanga, Ayacucho.

Koselleck, Reinhart. 1993. Futuro pasado. Para una semántica de los tiempos históricos. Paidós. Buenos Aires.

Langebaek, CarL. 1987. Mercados, poblamiento e integración étnica entre los muiscas -siglo XVI. Banco de la República. Bogotá.

Leal, Claudia. 2002. "La naturaleza en los estudios sociales". En Germán Palacio y Astrid Ulloa (eds.). Repensando la naturaleza. Encuentros y desencuentros disciplinarios en torno a lo ambiental. Universidad Nacional de Colombia, sede Leticia.Instituto Amazónico de Investigaciones, Imani.Icanh. Bogotá. 
LONDOÑo, EduARDO. 1989. "Santuarios, santillos, tunjos: objetos votivos de los muiscas en el siglo XVI”. Boletín Museo del Oro. 25.

Machado, Absalón y Jorge Torres. 1987. El sistema agroalimentario. Siglo XXI Editores. Bogotá.

Mariño, Margarita y César Peña. 2002. Atlas histórico de Bogotá I etapa: Guía histórica y descriptiva de la ciudad construida en la Colonia. Secretaría de Gobierno, Alcaldía Mayor de Bogotá. Bogotá.

Mesa, Claudia et al. (comps.) 2005. Región, ciudad y áreas protegidas. Manejo ambiental y participativo. Fescol. Bogotá.

Piedrahíta, Lucas Fernández de. I973 (i666). Noticia Historial de las Conquistas del Nuevo Reino de Granada (2 vols.). Instituto Colombiano de Cultura Hispánica. Bogotá.

RAMíREZ, ANDRÉS 2005. "Usos del paisaje, actores y percepción ambiental en la cuenca alta del río Teusacá, Bogotá”. En Claudia Mesa et al (comp.). Región, ciudad y áreas protegidas. Manejo ambiental y participativo. Fescol. Bogotá.

.2003. "Caracterización de los sistemas de alteridad en la cuenca alta del río Teusacá”. Informe final Plan de ordenamiento y manejo de los cerros Orientales (Pomco). Departamento Administrativo del Medio Ambiente. Bogotá.

RivadENEIRA, RicARDO. 2004. "Santa Fe de Bogotá desde sus orígenes, nacida para ser capital”. El Tiempo. II de agosto.

SANCLEMENTE, GLORIA. 2004. "Reserva forestal protectora bosque oriental de Bogotá, conflictos de uso y propuestas de solución en el proyecto de ley forestal para Colombia”. En Memorias del primer encuentro andino de derecho forestal con enfoque comunitario. Quito.

Sauer, Carl. I963. "Historical geography and the Western frontier". En J. Leighly (ed.). Land and life: A selection from the writings of Carl Sauer. University of California Press. Berkeley.

SAURí, DAVID y MARTí BOADA. 2006. "Sostenibilidad y cultura campesina: hacia modelos alternativos de desarrollo rural. Una propuesta desde Cataluña”. Boletín de la Asociación de Geógrafos Españoles. 41.

SEdrez, Lise. 2002. "Historia ambiental de América Latina: origen, principales interrogantes y lagunas”. En Germán Palacio y Astrid Ulloa (eds.). Repensando la naturaleza. Encuentros y desencuentros disciplinarios entorno a lo ambiental. Universidad Nacional de Colombia, sede Leticia-Icanh. Bogotá.

SHAnin, TEODOR. I980. Definiendo al campesinado: conceptualizaciones y descontextualizaciones. Pasado y presente en un debate marxista. Fondo de Cultura Económica. México. 
Simón, Fray Pedro ig8i (I625). Noticias historiales de las conquistas de Tierra Firme en los Indios Occidentales (7 vols.). Biblioteca del Banco Popular. Bogotá.

Teusacá (autor anónimo). 1997. "El Verjón, último de los cafuches". Monografía presentada al concurso de historia barrial. Bogotá.

Therrien, MóniKa, I992. "Persistencia de prácticas indígenas durante la colonia en el altiplano cundiboyacense”. Ponencia presentada al simposio Los chibchas de los Andes orientales, organizado por el Museo del Oro en el vi Congreso de antropología en Colombia (Universidad de los Andes, Bogotá , junio de I992). http://www.lablaa. org/blaavirtual/credencial/eneroig9oı.thm.

TOCANCIPÁ-FALLA, JAIRO. 2005. "El retorno de lo campesino: una revisión de los esencialismos y heterogeneidades en antropología”. Revista Colombiana de Antropología. 4I.

TRejos, LuIs. “La mita urbana”. Bitácoras de Bogotá. bitacorasdebogota. blogspot.com/2006/o9/la-mita-urbana.html

UnIVERSIDAD DE LOS ANDES. I999. "Estudio histórico de los cerros Orientales de Santa Fe de Bogotá”. Entrega final. Centro de Investigaciones de la Facultad de Arquitectura, Cifa. Instituto Distrital de Cultura y Turismo. Bogotá.

VARGAS, Julián y MARTA Zambrano. I990. "La población indígena en Santafé”. En La sociedad de Santa Fe colonial. Cinep. Bogotá.

VÉLEZ, GeRmán. 2005. "El Congreso de la República, aprueba la ley forestal. Sólo falta la aprobación en plenaria de la Cámara”. www. semillas. org.co

Wiesner, DiAna et al. 2008. "Los caminos de los cerros". Publicaciones digitales en la página de la Secretaría Distrital de Planeación www. dapd.gov.co/www/resources/los-caminos_general_y_norte.pdf - 